\title{
Computational Efficiency of Decoupling Approach in Solving Reactive Transport Model: A Case Study of Pyrite Oxidative Dissolution
}

\author{
Jixiang Huo, ${ }^{1}$ Fuheng Ma, ${ }^{1}$ and Hanzhou Song ${ }^{2}$ \\ ${ }^{1}$ State Key Laboratory of Hydrology-Water Resources and Hydraulic Engineering, Nanjing Hydraulic Research Institute, \\ Nanjing 210029, China \\ ${ }^{2}$ College of Earth Science and Engineering, Hohai University, Nanjing 210098, China
}

Correspondence should be addressed to Jixiang Huo; jixianghuo@hotmail.com

Received 13 July 2017; Revised 5 October 2017; Accepted 7 November 2017; Published 26 November 2017

Academic Editor: Keni Zhang

Copyright (c) 2017 Jixiang Huo et al. This is an open access article distributed under the Creative Commons Attribution License, which permits unrestricted use, distribution, and reproduction in any medium, provided the original work is properly cited.

Pyrite existed widely in nature and its oxidative dissolution might lead groundwater to become acidic, which was harmful to the environment and indeed to artificial building materials. The reactive transport model was a useful tool to predict the extent of such pollution. However, the chemical species were coupled together in the form of a reaction term, which might lead the equations to be nonlinear and thus difficult to solve. A decoupling approach was presented: linear algebraic manipulations of the stoichiometric coefficients of the chemical reactions for the purpose of reducing the number of equation variables and simplifying the reactive source were used. Then the original and decoupled models were solved separately, by both a direct solver and an iterative solver. By comparing the solution times of two models, it was shown that the decoupling approach could enhance the computational efficiency, especially in situations using denser meshes. Using a direct solver, more solution time was saved than when using an iterative version.

\section{Introduction}

Pyrite is a common, naturally occurring mineral. In the open atmosphere pyrite oxidative dissolution occurs under the action of groundwater. On one hand the resulting acid water may cause environmental problems, such as contamination of surface and ground waters directed to urban and agricultural supply [1-3]. Some toxic elements especially, such as arsenic, are closely associated with pyrite. The kinetic oxidative dissolution of As-bearing pyrite due to dissolved oxygen in the ambient groundwater is an important mechanism for arsenic release in groundwater under both natural conditions and engineering applications $[4,5]$. On the other hand the formation of acid water also has some impacts on artificial building materials because of sulfate attack and acid attack $[6,7]$. All the above lead the management of potentially acid generating waste rock to be very important [8]. To study the extent and scope of acidic water pollution, some hydrogeochemical models and transport ones are developed to simulate such a system [9-11].

In recent years reactive transport model is widely used to simulate the contaminant transport, water-rock interaction, and other processes in earth science fields $[12,13]$. To improve computational efficiency of the model, Friedly and Rubin [14] present a general, concise formulation (decoupling approach) by means of linear algebraic manipulations of the stoichiometric coefficients of the chemical reactions, which can reduce the number of unknown variables and simplify the reaction source/sink terms. Based on this, De Simoni et al. [15] and Molins and Mayer [16] build up the decoupling matrix according to the equilibrium and kinetic reactions. And Huo et al. [17] extend its applications to heterogeneous media. Some efficiency tests are done by Kräutle and Knabner [18] and Hoffmann et al. [19] to study the resulting improvement. In recent years, the decoupling approach is widely used in both engineering applications and laboratory 
experiments. Saaltink et al. [20] apply the approach into the modelling of multiphase flow for $\mathrm{CO}_{2}$ injection and storage in deep saline aquifers. And the approach is also used in the simulation of two-phase multicomponent flow with reactive transport in porous media [21, 22]. And in identifying geochemical processes using end member mixing analysis, Pelizardi et al. [23] uses the decoupling approach to help in the identification of both end members and such reactions, so as to improve mixing ratio calculations. In laboratory experiments and its simulation, the approach is applied in a laboratory experiment where a sand column saturated with a $\mathrm{MgSO}_{4}$ solution is subject to evaporation [24]. And some programs and models are built up based on the decoupling approach for hydrogeochemical calculations, such as CHEPROO++ [25] and MRWM [26].

In this paper, a reactive transport model of pyrite oxidative dissolution is built up in COMSOL Multiphysics, a finite element software platform for the simulation of physicsbased problems. COMSOL is a multiphysics modelling tool that solves various coupled physical problems based on Finite Element Analysis and Partial Differential Equations. It provides a user-friendly interface for mesh generation, equations configuration, and results visualization. And it is widely applied in earth science field. For example, Shao et al. [27] uses it to couple a dual-permeability model with a soil mechanics model for landslide stability evaluation on a hillslope scale. Azad et al. [28] build up an interface between COMSOL and GEMS, a chemical modelling platform, for the reactive transport modelling in variably saturated porous media, while Nardi et al. [29] and Jara et al. [30] couple two standalone simulation programs, COMSOL and PHREEQC, for the reactive transport modelling.

Although some studies have been done on computational efficiency, they are carried out from different research directions. Hoffmann et al. [19] mainly study the impact from theory view, while Kräutle and Knabner' work [18] is based on a transient model to study computational efficiency in different time steps of two approaches. In this paper, we focused on the number of meshes and different solvers. Based on a brief introduction to the theories and mathematical methods behind the decoupling approach, a reactive transport model of pyrite oxidative dissolution is solved by a traditional method and a decoupling approach separately to compare their computational efficiencies. In both $1 \mathrm{D}$ and $2 \mathrm{D}$ models, the study area is meshed to different grid refinements in each situation. The original and decoupled models are solved and their solution times are compared. Meanwhile, the 2D models are solved by both a direct and an iterative solver to study the effect on the computational efficiency of the decoupling approach compared to different solvers. It is aimed at providing a more convenient and efficient method of calculation to solve the reactive transport model of pyrite oxidative dissolution.

\section{Mathematical Description}

The chemical reactions involved in aqueous species are divided into two kinds, equilibrium reaction and kinetic one. Reaction rates of the former are fast in comparison to transport, so that local chemical equilibrium can be assumed at every point within the system. Kinetic laws are applied to represent the processes of latter one, which is not sufficiently fast enough. So without considering the influence of activity, the mass balance of each species can be written in concise vector notation as follows:

$$
\frac{\partial(\mathbf{m})}{\partial t}=\mathbf{M} L(\mathbf{c})+S^{T} \cdot \mathbf{r}=\mathbf{M} L(\mathbf{c})+\mathbf{S}_{e}^{T} \mathbf{r}_{e}+\mathbf{S}_{k}^{T} \mathbf{r}_{k},
$$

where vector $\mathbf{m}$ contains the mass of species per unit volume of porous medium, and it can be split into two parts, $\mathbf{m}_{c}$ and $\mathbf{m}_{a}$, respectively, related to the constant activity species (such as minerals in solid phase and gases) and to the remaining species. Matrix $\mathbf{M}$ is diagonal and its diagonal terms are unity when a given species is mobile and zero otherwise. $\mathbf{c}$ contains species concentrations in $\mathrm{mol} / \mathrm{mass}$ of liquid $(\mathbf{m}=$ $\theta \cdot \mathbf{c}$ for mobile species, $\theta$ is porosity) and $\mathbf{c}=\left(\begin{array}{ll}\mathbf{c}_{1} & \mathbf{c}_{2}\end{array}\right)^{T}$, while $\mathbf{c}_{1}, \mathbf{c}_{2}$ are primary and secondary species: the number of secondary species is equal to the number of reaction equilibrium, and the linear operator $L$ in (1) is defined as $L(\mathbf{c})=-\nabla \cdot(\mathbf{q} \cdot \mathbf{c})+\nabla \cdot(\theta \cdot \mathbf{D} \nabla \mathbf{c})$, where $\mathbf{q}$ is the water flux and $\mathbf{D}$ is dispersion coefficient; $\mathbf{S}$ is a matrix containing the stoichiometric coefficients of reactions involving reactants and product(s) and $\mathbf{S}=\left(\mathbf{S}_{e} / \mathbf{S}_{k}\right)$, where $\mathbf{S}_{e}$ and $\mathbf{S}_{k}$ represent the matrices of equilibrium and kinetic reactions such that $\mathbf{S}_{e}=\left(\mathbf{S}_{1} \mid \mathbf{S}_{2}\right)$ due to the primary and secondary species. $\mathbf{S}_{1}$ is stoichiometric coefficients matrix of primary species and $\mathrm{S}_{2}$ is stoichiometric coefficients matrix of secondary species. Vector $\mathbf{r}$ contains the reaction rate and is also divided into two parts: $\mathbf{r}_{e}$ and $\mathbf{r}_{k}$.

A full rank matrix, $\mathbf{U}$, can be established, orthogonal to $\mathbf{S}_{e}$, which satisfies $\mathbf{U} \cdot \mathbf{S}_{e}{ }^{T}=0$. The component matrix $\mathbf{U}$ can be calculated by means of Gauss-Jordan elimination which leads to the following expression [31]:

$$
\mathbf{U}=\left[\mathbf{I}_{N_{s}-N_{e}} \mid-\mathbf{S}_{1}^{T} \cdot\left(\mathbf{S}_{2}^{T}\right)^{-1}\right],
$$

where $\mathbf{I}_{N_{s}-N_{e}}$ is a diagonal matrix of dimension $N_{s}-N_{e}$, with all diagonal elements equal to one; $N_{e}$ and $N_{s}$ are the number of reactions and species. Now a component vector of $\mathbf{u}$ is defined as $\mathbf{u}=\mathbf{U} \cdot \mathbf{c}$ and its number, $N_{u}$, can be calculated by $N_{u}=N_{s}-N_{e}$. Writing the transport equations in terms of $\mathbf{u}$ is helpful because the source/sink term becomes simple. Species concentration $\mathbf{c}$ can also be solved with the equilibrium reaction constants.

According to Molins et al. [32], four types of reactive transport systems are classified by the types of reactions, as shown in Table 1.

It can be seen that four types of reactive transport systems are classified. The characteristics and calculation of component matrix $\mathbf{U}$ of each system are shown as follows.

(1) The first is tank system, in which all reactions take place in equilibrium in the aqueous phase, which means a large aqueous reservoir with residence times long enough for aqueous species to reach equilibrium, and no interaction with other solid or gas phases assumed. The component matrix 
TABLE 1: Types of reactive transport system.

\begin{tabular}{lcccc}
\hline & \multicolumn{2}{c}{ Homogeneous } & \multicolumn{2}{c}{ Heterogeneous } \\
Paradigm & $\begin{array}{c}\text { Fast } \\
\text { (Equilibrium) }\end{array}$ & $\begin{array}{c}\text { Slow } \\
\text { (Kinetic) }\end{array}$ & $\begin{array}{c}\text { Fast } \\
\text { (Equilibrium) }\end{array}$ & $\begin{array}{c}\text { Slow } \\
\text { (Kinetic) }\end{array}$ \\
\hline Tank & $\sqrt{ }$ & & & \\
Canal & $\sqrt{ }$ & $\sqrt{ }$ & & \\
River & $\sqrt{ }$ & $\sqrt{ }$ & & $\sqrt{ }$ \\
Aquifer & $\sqrt{ }$ & $\sqrt{ }$ & $\sqrt{ }$ & $\sqrt{ }$ \\
\hline
\end{tabular}

of this system, $\mathbf{U}^{\text {tank}}$, can be calculated by the following equation.

$$
\mathbf{U}^{\text {tank }}=\mathbf{U}^{e}=\left[\begin{array}{ll}
\mathbf{I} & \mathbf{S}_{e 1}^{t}
\end{array}\right],
$$

where $\mathbf{S}_{e 1}^{t}$ is stoichiometric coefficients matrix of equilibrium reactions corresponding to primary species.

(2) The second is canal system, in which all reactions are homogeneous, but some may be slow (kinetic). The component matrix of this system, $\mathbf{U}^{\text {Canal }}$, can be calculated by the following equation.

$$
\mathbf{U}^{\text {Canal }}=\mathbf{U}_{k} \cdot \mathbf{U}_{e},
$$

where $\mathbf{U}_{k}=\left[\begin{array}{cc}\mathbf{I} & \mathbf{S}_{k 1}^{t} \\ 0 & \mathrm{I}\end{array}\right]$ and $\mathbf{S}_{k 1}^{t}$ is stoichiometric coefficients matrix of kinetic reactions corresponding to primary species.

(3) The third is river system, in which heterogeneous reactions also take place, but they are slow relative to flow. The component matrix of this system, $\mathbf{U}^{\text {River }}$, can be calculated by the following equation.

$$
\mathbf{U}^{\text {river }}=\mathbf{F} \cdot \mathbf{U}^{\text {canal }},
$$

where $\mathbf{F}$ is a factor matrix which is multiplied by $\mathbf{U}^{\text {Canal }}$ to eliminate the immobile kinetic species. More detailed solution steps of $\mathbf{F}$ can be seen in Molins et al. [32].

(4) The fourth is aquifer system, where some heterogeneous reactions are fast enough to be considered in equilibrium. Some fixed activity species (e.g., minerals and $\mathrm{H} 2 \mathrm{O}$ ) can be found among the equilibrium reactions. These species can be eliminated from the equations by reducing the components to be solved. The component matrix of this system, $\mathbf{U}^{\text {Aquifer }}$, can be calculated by the following equation.

$$
\mathbf{U}^{\text {Aquifer }}=\mathbf{E} \cdot \mathbf{U}^{\text {River }},
$$

where $\mathbf{E}$ is a factor matrix which is multiplied by $\mathbf{U}^{\text {River }}$ to eliminate constant activity species and reduce the number of components. More detailed solution steps of $\mathbf{E}$ can be seen in Molins et al. [32].

\section{Decoupling Approach in Pyrite Oxidative Dissolution}

3.1. The Chemical System and Its Decoupling Matrix. It is important to build up a chemical reaction system for pyrite oxidative dissolution reactive transport. When the initial solution is assumed to be formed in deionized water, the main reactions occurring in the open system are as follows.

$$
\begin{gathered}
\mathrm{O}_{2}(\mathrm{~g}) \Longleftrightarrow \mathrm{O}_{2}(\mathrm{aq}) \\
\mathrm{H}_{2} \mathrm{O} \Longleftrightarrow \mathrm{H}^{+}+\mathrm{OH}^{-} \\
\mathrm{FeS}_{2}+3.75 \mathrm{O}_{2}(\mathrm{aq})+0.5 \mathrm{H}_{2} \mathrm{O} \Longrightarrow \\
\mathrm{Fe}^{3+}+2 \mathrm{SO}_{4}{ }^{2-}+\mathrm{H}^{+}
\end{gathered}
$$

where there are equilibrium reactions in both (7) and (8), with reaction rates of $R_{1}$ and $R_{2}$ and (9) reflects the process of pyrite oxidative dissolution, which depends on the concentration of $\mathrm{H}^{+}$and $\mathrm{O}_{2}(\mathrm{aq})$ in solution. According to these, the stoichiometric coefficient matrix of the system $\mathbf{S}$ could be written as

S

$$
\begin{aligned}
& \mathrm{O}_{2}(\mathrm{aq}) \mathrm{H}^{+} \mathrm{OH}^{-} \mathrm{SO}_{4}{ }^{2-} \mathrm{Fe}^{3+} \mathrm{FeS}_{2} \mathrm{O}_{2}(\mathrm{~g}) \mathrm{H}_{2} \mathrm{O} \\
& =\left[\begin{array}{cccccccc}
1 & 0 & 0 & 0 & 0 & 0 & -1 & 0 \\
0 & 1 & 1 & 0 & 0 & 0 & 0 & -1 \\
-3.75 & 1 & 0 & 2 & 1 & -1 & 0 & -0.5
\end{array}\right]
\end{aligned}
$$

Since the reactions involved both aqueous and solid phases, it satisfied the aquifer system in Section 2. So the component matrix, $\mathbf{U}$, could be calculated as

$$
\mathbf{U}=\left[\begin{array}{cccccccc}
0 & -1 & 1 & 0 & 1 & 0 & 0 & 0 \\
0 & 0 & 0 & 1 & -2 & 0 & 0 & 0 \\
0 & 0 & 0 & 0 & 1 & 0 & 0 & 0
\end{array}\right] .
$$

And a new vector of components, $\mathbf{u}$, was defined as

$$
\mathbf{u}=U \cdot \mathbf{c}=\left[\begin{array}{c}
-c_{2}+c_{3}+c_{5} \\
c_{4}-2 \cdot c_{5} \\
c_{5}
\end{array}\right]=\left[\begin{array}{l}
u_{1} \\
u_{2} \\
u_{3}
\end{array}\right],
$$

where the vector $\mathbf{c}$ in this system comprised eight species: $\mathrm{O}_{2}(\mathrm{aq}), \mathrm{H}^{+}, \mathrm{OH}^{-}, \mathrm{SO}_{4}{ }^{2-}, \mathrm{Fe}^{3+}, \mathrm{FeS}_{2}, \mathrm{O}_{2}(\mathrm{~g})$, and $\mathrm{H}_{2} \mathrm{O}$ in order. The calculated aqueous components were $u_{1}, u_{2}, u_{3}$. As (12) shows (1) the component vector $\mathbf{u}$ is a linear combination of species, which is readily calculated; (2) the number of unknowns to be solved in the equations is reduced, from eight species to three components. In this system, the number of all species is defined as $N_{s}$, with $N_{s}=8$ and the number of equilibrium reactions $N_{e}$ is 2 , while the number of secondary species with fixed activity is defined as $N_{0}$, which includes pyrite, $\mathrm{H}_{2} \mathrm{O}$, and $\mathrm{O}_{2}(\mathrm{~g})$. In this system $\mathrm{N}_{0}=3$, so the number of components, $N_{c}$, could be calculated as

$$
N_{c}=N_{s}-N_{e}-N_{0}=8-2-3=3 .
$$

Meanwhile, the reaction terms of species in the transport equations were as follows:

$$
\begin{aligned}
S^{T} \cdot R= & {\left[R_{1}-3.75 \cdot R_{3}, R_{2}+R_{3}, R_{2}, 2 \cdot R_{3}, R_{3},-R_{3},\right.} \\
- & \left.R_{1},-R_{2}-0.5 \cdot R_{3}\right]^{T} .
\end{aligned}
$$


TABLE 2: Chemical parameters of pyrite oxidation dissolution.

\begin{tabular}{lcccc}
\hline$K_{\text {sp } 1}$ & $K_{\text {sp2 }}$ & $k$ & $m$ & $n$ \\
\hline $10^{-2.8983}$ & $10^{-14}$ & $10^{-10.19}$ & 0.5 & -0.11 \\
\hline
\end{tabular}

Multiplying by the decoupling matrix, $U$, this term could be expressed as

$$
U \cdot S^{T} \cdot R=\left[\begin{array}{lll}
0 & 0 & 0 \\
0 & 0 & 0 \\
0 & 0 & 1
\end{array}\right] \cdot\left[\begin{array}{l}
R_{1} \\
R_{2} \\
R_{3}
\end{array}\right]=\left[\begin{array}{c}
0 \\
0 \\
R_{3}
\end{array}\right] .
$$

It could be seen that the reaction term of the original model was more complicated and contained the expressions of the equilibrium reaction rates $R_{1}$ and $R_{2}$, both of which were difficult to obtain explicitly which introduced some difficulties when solving the model. However, it was expressed in the form of extremely simple items by means of the decoupling approach. As shown in (15), the reaction terms of components, $u_{1}$ and $u_{2}$, were 0 , and the one of component $u_{3}$ involved only $R_{3}$. Then the transport equations of component $\mathbf{u}$ could be solved. Once system components had been evaluated, the original species, $c$, was obtained from the nonlinear algebraic system of (12) and corresponding equilibrium constants of (7) and (8).

3.2. Verification. In order to verify the influence of the decoupling approach on the calculation accuracy, firstly a batch reactor system of pyrite oxidation dissolution was taken as an example. In this system the pyrite was completely immersed in deionized water in a stirred vessel, which meant there was no need to consider the transport problem. The simulation results by both original approach and decoupling one were compared. The chemical parameters are shown in Table 2.

$K_{\mathrm{sp} 1}$ and $K_{\mathrm{sp} 2}$ are the equilibrium constant of (7) and (8), while $k, m$, and $n$ are reaction parameters of pyrite oxidative dissolution. Its reaction rate could be calculated by the following equation.

$$
R_{3}=\frac{A_{\text {solid }}}{V_{\text {water }}} \cdot k \cdot c_{1}^{m} \cdot c_{2}^{n}
$$

where $A_{\text {solid }}$ is solid phase surface area and $V_{\text {water }}$ is water volume; $c_{1}$ and $c_{2}$ are concentration of $\mathrm{O}_{2}(\mathrm{aq})$ and $\mathrm{H}^{+}$.

The ratio of solid phase surface area to water volume was set as $3 \mathrm{dm}^{-1}$ and simulated time was 10 days. The variation and error of $\mathrm{pH}$ value and $\mathrm{Fe}^{3+}$ concentration in two models are shown in Figure 1.

It can be seen from Figure 1 that the results of two models are basically the same. Maximum relative error of $\mathrm{pH}$ value is $-0.04725 \%$, while the one of $\mathrm{Fe}^{3+}$ is $0.59542 \%$, which means that decoupling approach has little effect on the accuracy of the calculation.

3.3. Comparison of Computational Efficiency. The decoupling approach not only simplified the reaction term but also reduced the number of unknown variables in the transport equations. As a result, the new transport model of each component should now be solvable with improved computational efficiency. Deionized water flows through a single smooth fracture of pyrite can be simplified to either a 1D or 2D parallel plate model with model parameters as shown in Table 3.

Initially the fracture was deemed to have been full of deionized water, with a constant flow velocity $v$ through the fracture. Without considering the change in the aperture size caused by dissolution, the distribution of aqueous species reached dynamic equilibrium, which can be regarded as a steady state. The two models were thus simulated. One of the two models involved transport of species $\mathbf{c}$ and the original model was designated: the other involved transport of decoupled component $\mathbf{u}$ and the decoupled model was designated.

Then the two models were separately established in COMSOL $3.5 \mathrm{a}$, a software platform for the simulation of physics-based problems. The central processing unit (CPU) of the computer was an Intel Core Duo P8400 with a clock speed of $2.26 \mathrm{GHz}$ and the motherboard had $3 \mathrm{~GB}$ of random access memory. There were two main categories of solver in the software: direct and iterative. The former included UMFPACK, SPOOLES, PARDISO, and TAUCS Cholesky, which solved a linear system by Gaussian elimination. The iterative solvers, GMRES, FGMRES, conjugate gradients, BiCGStab, and geometric multigrid, were more memoryefficient to deal with models with many degrees of freedom.

When the model was solved in COMSOL, the mesh generator partitioned the study domains into mesh elements: the number of elements depended on the maximum element size when they were uniformly subdivided. Then the 1D and 2D models (original and decoupled types) were solved separately. First the direct solver, UMFPACK, was chosen and the model was solved three times in each case. To solve the nonlinear equations in both original model and decoupled one, Damped Newton Method (DNM) was adopted. Relative tolerance was set as $1.0 \times 10^{-6}$ and maximum number of iterations was set as 25 . The average solution times are shown in Tables 4 and 5.

It can be seen from Tables 4 and 5 that:

(1) Solution by direct solver, UMFPACK, costs much more time in the original model than when adopting a decoupling approach in both $1 \mathrm{D}$ and 2D models.

(2) The solution time in both 1D models increases with the number of elements, but it saves more time by using a decoupling approach when the number of elements becomes large. When there are only 25 elements in the model, it costs $0.234 \mathrm{~s}$ and $0.094 \mathrm{~s}$ to solve each model. With the increase in the number of elements, the solution times reach $1.079 \mathrm{~s}$ and $0.297 \mathrm{~s}$ for 500 elements (some 4.61 and 3.16 times the requirements at 25 elements).

(3) As in $1 \mathrm{D}$, the computing time in $2 \mathrm{D}$ also increases with the number of elements in both of the two models and it saves more time when using a decoupling approach for large numbers of elements. At 7,800 elements, the original model cannot be solved due to an out of memory error during LU factorisation. However, by using a decoupling approach it only costs $21.033 \mathrm{~s}$. Compared to the $1 \mathrm{D}$ model, it has a better 

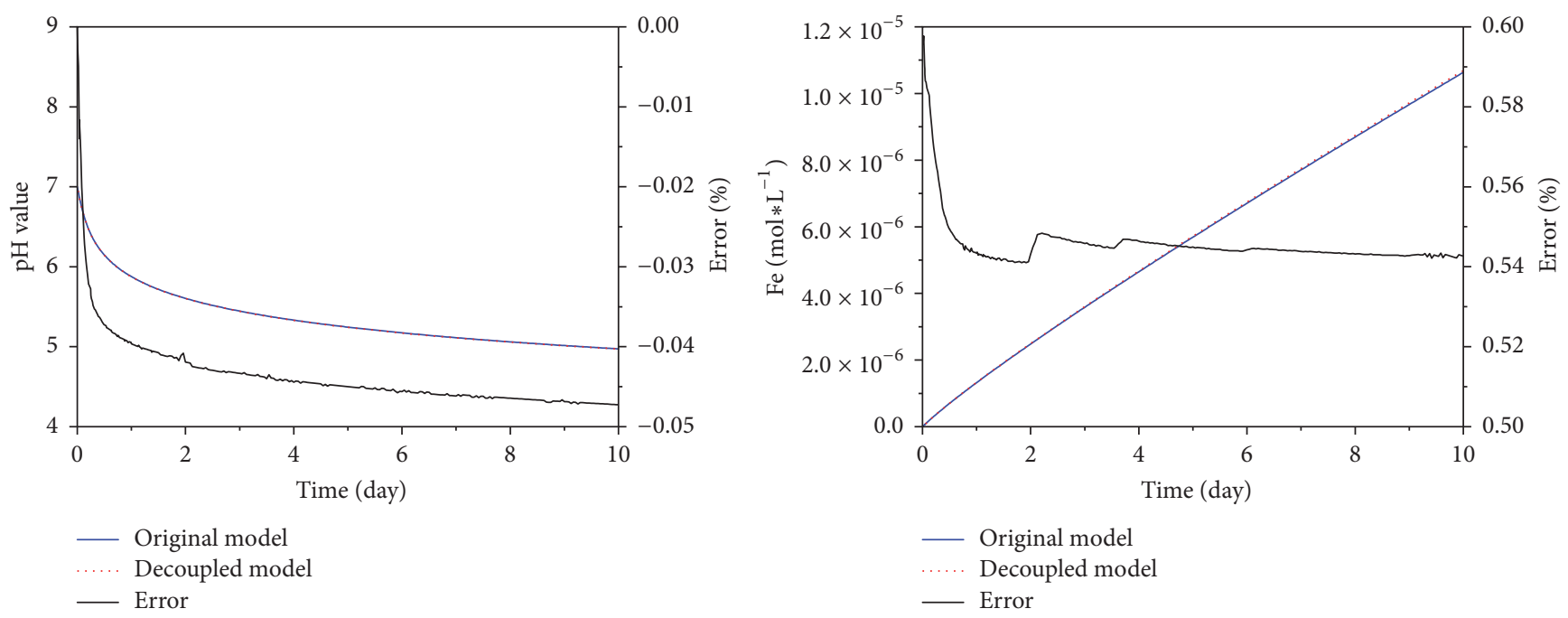

Figure 1: Variation and error of $\mathrm{pH}$ value and $\mathrm{Fe}^{3+}$ concentration.

TABLE 3: Parameters for the 1D and 2D models.

\begin{tabular}{cccccrr}
\hline & $L / \mathrm{m}$ & $W / \mathrm{m}$ & $v / \mathrm{m} \cdot \mathrm{s}^{-1}$ & $\alpha_{L} / \mathrm{m}$ & $\alpha_{T} / \mathrm{m}$ & $D_{m} / \mathrm{m}^{2} \cdot \mathrm{s}^{-1}$ \\
\hline 1D & 5 & - & 0.001 & 0.05 & - & $1.34 e-9$ \\
2D & 5 & 1 & 0.001 & 0.05 & 0.02 & $1.34 e-9$ \\
\hline
\end{tabular}

TABLE 4: Comparison of solution time in 1D model using direct solver, UMFPACK.

\begin{tabular}{lcccc}
\hline $\begin{array}{l}\text { Maximum } \\
\text { element size }\end{array}$ & $\begin{array}{c}\text { Number of } \\
\text { elements }\end{array}$ & $\begin{array}{c}\text { Original } \\
\text { solution time, } \\
t_{1} / \mathrm{s}\end{array}$ & $\begin{array}{c}\text { Decoupled } \\
\text { solution time, } \\
t_{2} / \mathrm{s}\end{array}$ & $\begin{array}{c}t_{2} / t_{1} \\
\%\end{array}$ \\
\hline 0.01 & 500 & 1.079 & 0.297 & 27.53 \\
0.02 & 250 & 0.625 & 0.203 & 32.48 \\
0.04 & 125 & 0.406 & 0.141 & 34.73 \\
0.05 & 100 & 0.359 & 0.125 & 34.82 \\
0.08 & 63 & 0.313 & 0.109 & 34.82 \\
0.10 & 50 & 0.282 & 0.109 & 38.65 \\
0.20 & 25 & 0.234 & 0.094 & 35.47 \\
\hline
\end{tabular}

computational efficiency costing only $4.78 \%$ to $27.71 \%$ of the original.

Then the iterative solver GMRES was chosen to solve the $2 \mathrm{D}$ model. The solution set of nonlinear equations was the same as the direct solver, UMFPACK. Three replicates were run and the average solution times are shown in Table 6.

The following can be seen from Table 6 .

(1) Like the results in Table 3, the decoupling approach also enhances the computational efficiency when solving the two models by use of the iterative solver. The decoupled solution time is only $17.92 \%$ to $52.34 \%$ of that needed for the original model and the solution time increases with the number of elements no matter whether in the original or decoupled model.

(2) Unlike the situation in Table $3, t_{2} / t_{1}$ does not reduce with increased numbers of elements: at 5,036 and 7,800
TABLE 5: Comparison of solution time in 2D model using direct solver, UMFPACK.

\begin{tabular}{lcccc}
\hline $\begin{array}{l}\text { Maximum } \\
\text { element size }\end{array}$ & $\begin{array}{c}\text { Number of } \\
\text { elements }\end{array}$ & $\begin{array}{c}\text { Original } \\
\text { solution time, } \\
t_{1} / \mathrm{s}\end{array}$ & $\begin{array}{c}\text { Decoupled } \\
\text { solution time, } \\
t_{2} / \mathrm{s}\end{array}$ & $\begin{array}{c}t_{2} / t_{1} \\
\%\end{array}$ \\
\hline 0.04 & 7800 & - & 21.033 & - \\
0.05 & 5036 & 246.141 & 11.767 & 4.78 \\
0.08 & 2038 & 43.644 & 4.141 & 9.49 \\
0.10 & 1310 & 18.095 & 2.344 & 12.95 \\
0.12 & 944 & 11.032 & 1.719 & 15.58 \\
0.15 & 616 & 6.062 & 1.141 & 18.82 \\
0.20 & 308 & 2.672 & 0.626 & 20.08 \\
0.25 & 206 & 1.750 & 0.485 & 23.43 \\
0.30 & 148 & 1.344 & 0.406 & 27.71 \\
\hline
\end{tabular}

- represents the absence of a result because of an out of memory error during LU factorisation.

elements, $t_{2} / t_{1}$ is only $51.54 \%$ and $52.34 \%$ of that required originally. It shows that the decoupling approach does not have as significant an effect as expected when used iteratively on a large model.

(3) Solving the original model with a direct solver costs much more time than when using an iterative version. However, when dealing with a decoupled model, the direct solver is faster and $t_{2} / t_{1}$ (Table 3) ranges from $4.78 \%$ to $27.71 \%$, while it is $17.92 \%$ to $52.34 \%$ in Table 4 . This means that solving the decoupled model by using an iterative solver does not save as much time as the direct solver does. 
TABLE 6: Comparison of solution time in 2D model using iterative solver, GMRES.

\begin{tabular}{lcccc}
\hline $\begin{array}{l}\text { Maximum } \\
\text { element size }\end{array}$ & $\begin{array}{c}\text { Number of } \\
\text { elements }\end{array}$ & $\begin{array}{c}\text { Original } \\
\text { solution time, } \\
t_{1} / \mathrm{s}\end{array}$ & $\begin{array}{c}\text { Decoupled } \\
\text { solution time, } \\
t_{2} / \mathrm{s}\end{array}$ & $\begin{array}{c}t_{2} / t_{1} \\
\%\end{array}$ \\
\hline 0.04 & 7800 & 89.644 & 46.923 & 52.34 \\
0.05 & 5036 & 50.955 & 26.313 & 51.64 \\
0.08 & 2038 & 18.251 & 8.235 & 45.12 \\
0.10 & 1310 & 11.016 & 5.062 & 45.95 \\
0.12 & 944 & 7.328 & 3.454 & 47.13 \\
0.15 & 616 & 4.531 & 0.812 & 17.92 \\
0.20 & 308 & 2.172 & 0.484 & 22.28 \\
0.25 & 206 & 1.547 & 0.406 & 26.24 \\
0.30 & 148 & 1.219 & 0.360 & 29.53 \\
\hline
\end{tabular}

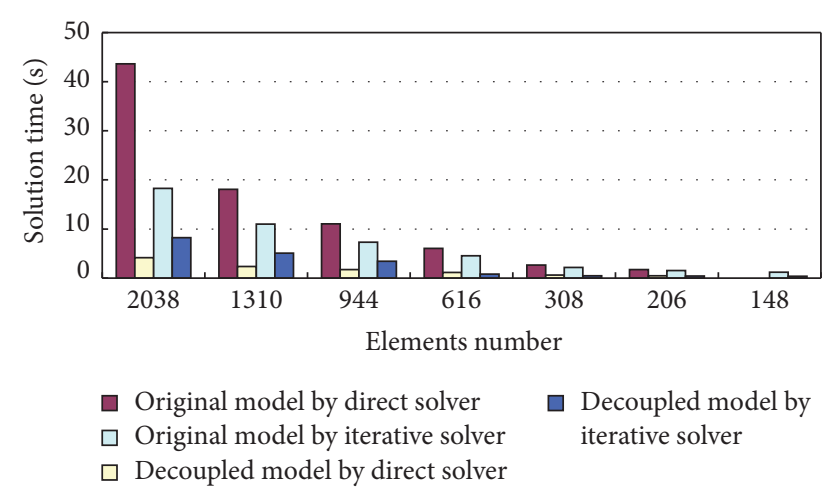

FIGURE 2: Comparison of solution times.

According to Tables 5 and 6 , solution times for original and decoupled models with direct and iterative solvers are shown in Figure 2.

Figure 2 shows that solving an original model takes more time than a decoupled one, no matter whether by direct solver or iterative solver. In general sorted by time taken: the decoupled model by direct solver $<$ decoupled model by iterative solver $<$ original model by iterative solver $<$ original model by direct solver.

\section{Conclusions}

The present work described the basic theory and mathematical methods of the decoupling approach and then took pyrite oxidative dissolution as an example. Based on the analysis of its chemical reaction system, the decoupling matrix $U$ was calculated. When multiplied by $U$, the concentration vector $\mathbf{c}$ was converted to the component vector $\mathbf{u}$, which had fewer variables and simpler reaction terms. Then the original and decoupled models were established in COMSOL Multiphysics 3.5a. Then the study domain was meshed at different degrees of refinement. In each case it was solved by direct and iterative solvers. The results show the following.

(1) Decoupling enhances the computational efficiency in both $1 \mathrm{D}$ and 2D models while saving more time for 2D models than $1 \mathrm{D}$ models.
(2) The more mesh grids the domain generates, the more efficiently the decoupled model finds a solution by direct solver, whether in $1 \mathrm{D}$ or $2 \mathrm{D}$.

(3) Although the iterative solver takes less time than the direct solver for the original 2D model, it is more efficient to use a direct solver in solving a decoupled problem.

(4) The solution times in ascending order are the decoupled model solved by direct solver, a decoupled model solved by an iterative solver, the original model solved by an iterative solver, and the original model solved by a direct solver.

As a conclusion, the decoupling approach is of assistance when solving reactive transport of pyrite oxidative dissolution problems, especially over a large domain with more mesh elements. Its applicability is thus demonstrated.

\section{Conflicts of Interest}

The authors declare that there are no conflicts of interest regarding the publication of this article.

\section{Acknowledgments}

This work was supported by Young Scientists Fund of the National Natural Science Foundation of China (Grant no. 51609150), the China Postdoctoral Science Foundation (Grant no. 2016M590477), the National Natural Science Foundation of China (Grant no. 41272265), and the Special Scientific Research Fund of Public Welfare Profession of Ministry of Water Resources of China (Grants nos. 201501033 and 201501036).

\section{References}

[1] J. A. Grande, R. Beltrán, A. Sáinz, J. C. Santos, M. L. De La Torre, and J. Borrego, "Acid mine drainage and acid rock drainage processes in the environment of Herrerías Mine (Iberian Pyrite Belt, Huelva-Spain) and impact on the Andevalo Dam," Environmental Geology, vol. 47, no. 2, pp. 185-196, 2005.

[2] J. A. Grande, M. Santisteban, M. L. de la Torre, T. Valente, and E. Pérez-Ostalé, "Characterisation of AMD Pollution in the Reservoirs of the Iberian Pyrite Belt," Mine Water and the Environment, vol. 32, no. 4, pp. 321-330, 2013.

[3] P. M. Heikkinen, M. L. Räisänen, and R. H. Johnson, "Geochemical characterisation of seepage and drainage water quality from two sulphide mine tailings impoundments: Acid mine drainage versus neutral mine drainage," Mine Water and the Environment, vol. 28, no. 1, pp. 30-49, 2009.

[4] M. M. Rahman, M. Bakker, C. H. L. Patty et al., "Reactive transport modeling of subsurface arsenic removal systems in rural Bangladesh," Science of the Total Environment, vol. 537, pp. 277-293, 2015.

[5] S. Fakhreddine, J. Lee, P. K. Kitanidis, S. Fendorf, and M. Rolle, "Imaging geochemical heterogeneities using inverse reactive transport modeling: An example relevant for characterizing arsenic mobilization and distribution," Advances in Water Resources, vol. 88, pp. 186-197, 2016.

[6] A. Rodrigues, J. Duchesne, B. Fournier, B. Durand, P. Rivard, and M. Shehata, "Mineralogical and chemical assessment of 
concrete damaged by the oxidation of sulfide-bearing aggregates: Importance of thaumasite formation on reaction mechanisms," Cement and Concrete Research, vol. 42, no. 10, pp. 13361347, 2012.

[7] T. Schmidt, A. Leemann, E. Gallucci, and K. Scrivener, "Physical and microstructural aspects of iron sulfide degradation in concrete," Cement and Concrete Research, vol. 41, no. 3, pp. 263269, 2011.

[8] M. F. Lengke, A. Davis, and C. Bucknam, "Improving management of potentially acid generating waste rock," Mine Water and the Environment, vol. 29, no. 1, pp. 29-44, 2010.

[9] C. Kohfahl and A. Pekdeger, "Rising groundwater tables in partly oxidized pyrite bearing dump-sediments: Column study and modelling approach," Journal of Hydrology, vol. 331, no. 3-4, pp. 703-718, 2006.

[10] B. Blunden and B. Indraratna, "Pyrite oxidation model for assessing ground-water management strategies in acid sulfate soils," Journal of Geotechnical and Geoenvironmental Engineering, vol. 127, no. 2, pp. 146-157, 2001.

[11] R. Abbassi, F. Khan, and K. Hawboldt, "Prediction of minerals producing acid mine drainage using a computer-assisted thermodynamic chemical equilibrium model," Mine Water and the Environment, vol. 28, no. 1, pp. 74-78, 2009.

[12] C. I. Steefel, D. J. DePaolo, and P. C. Lichtner, "Reactive transport modeling: An essential tool and a new research approach for the Earth sciences," Earth and Planetary Science Letters, vol. 240, no. 3-4, pp. 539-558, 2005.

[13] C. I. Steefel, C. A. Appelo, and B. Arora, "Reactive transport codes for subsurface environmental simulation," Computational Geosciences, vol. 19, no. 3, pp. 445-478, 2015.

[14] J. C. Friedly and J. Rubin, "Solute transport with multiple equilibrium-controlled or kinetically controlled chemical reactions," Water Resources Research, vol. 28, no. 7, pp. 1935-1953, 1992.

[15] M. De Simoni, J. Carrera, X. Sánchez-Vila, and A. Guadagnini, "A procedure for the solution of multicomponent reactive transport problems," Water Resources Research, vol. 41, no. 11, Article ID W11410, pp. 1-16, 2005.

[16] S. Molins and K. U. Mayer, "Coupling between geochemical reactions and multicomponent gas and solute transport in unsaturated media: A reactive transport modeling study," Water Resources Research, vol. 43, no. 5, Article ID W05435, 2007.

[17] J.-X. Huo, H.-Z. Song, and Z.-W. Wu, "Multi-component reactive transport in heterogeneous media and its decoupling solution," Journal of Contaminant Hydrology, vol. 166, pp. 11-22, 2014.

[18] S. Kräutle and P. Knabner, "A new numerical reduction scheme for fully coupled multicomponent transport-reaction problems in porous media," Water Resources Research, vol. 41, no. 9, Article ID W09414, pp. 1-17, 2005.

[19] J. Hoffmann, S. Kräutle, and P. Knabner, "A general reduction scheme for reactive transport in porous media," Computational Geosciences, vol. 16, no. 4, pp. 1081-1099, 2012.

[20] M. W. Saaltink, V. Vilarrasa, F. De Gaspari, O. Silva, J. Carrera, and T. S. Rötting, "A method for incorporating equilibrium chemical reactions into multiphase flow models for $\mathrm{CO} 2$ storage," Advances in Water Resources, vol. 62, pp. 431-441, 2013.

[21] E. Ahusborde, M. Kern, and V. Vostrikov, "Numerical simulation of two-phase multicomponent flow with reactive transport in porous media: application to geological sequestration of CO2," in Proceedings of the ESAIM: Proceedings and Surveys, vol. 50, pp. 21-39.
[22] E. Ahusborde and M. El Ossmani, "A sequential approach for numerical simulation of two-phase multicomponent flow with reactive transport in porous media," Mathematics and Computers in Simulation, vol. 137, pp. 71-89, 2017.

[23] F. Pelizardi, S. A. Bea, J. Carrera, and L. Vives, "Identifying geochemical processes using End Member Mixing Analysis to decouple chemical components for mixing ratio calculations," Journal of Hydrology, vol. 550, pp. 144-156, 2017.

[24] P. Gamazo, M. W. Saaltink, J. Carrera, L. Slooten, S. A. Bea, and M. Gran, "Modeling the influence of $\mathrm{MgSO} 4$ invariant points on multiphase reactive transport process during saline soil evaporation," Physics and Chemistry of the Earth, vol. 64, pp. 57-64, 2013.

[25] F. d. Gaspari, "Mixing and speciation algorithms for geochemical and reactive transport problems," 2015.

[26] J. Soler-Sagarra, L. Luquot, L. Martínez-Pérez, M. W. Saaltink, F. De Gaspari, and J. Carrera, "Simulation of chemical reaction localization using a multi-porosity reactive transport approach," International Journal of Greenhouse Gas Control, vol. 48, pp. 5968, 2016.

[27] W. Shao, T. Bogaard, and M. Bakker, "How to Use COMSOL Multiphysics for Coupled Dual-permeability Hydrological and Slope Stability Modeling," Procedia Earth and Planetary Science, vol. 9, pp. 83-90, 2014.

[28] V. J. Azad, C. Li, C. Verba, J. H. Ideker, and O. B. Isgor, "A COMSOL-GEMS interface for modeling coupled reactivetransport geochemical processes," Computers \& Geosciences, vol. 92, pp. 79-89, 2016.

[29] A. Nardi, A. Idiart, P. Trinchero, L. M. De Vries, and J. Molinero, "Interface COMSOL-PHREEQC (iCP), an efficient numerical framework for the solution of coupled multiphysics and geochemistry," Computers \& Geosciences, vol. 69, pp. 10-21, 2014.

[30] D. Jara, J.-R. d. Dreuzy, and B. Cochepin, “TReacLab, An objectoriented implementation of non-intrusive splitting methods to couple independent transport and geochemical software," Computers \& Geosciences.

[31] M. W. Saaltink, C. Ayora, and J. Carrera, "A mathematical formulation for reactive transport that eliminates mineral concentrations," Water Resources Research, vol. 34, no. 7, pp. 1649-1656, 1998.

[32] S. Molins, J. Carrera, C. Ayora, and M. W. Saaltink, "A formulation for decoupling components in reactive transport problems," Water Resources Research, vol. 40, no. 10, pp. W103011W1030113, 2004. 

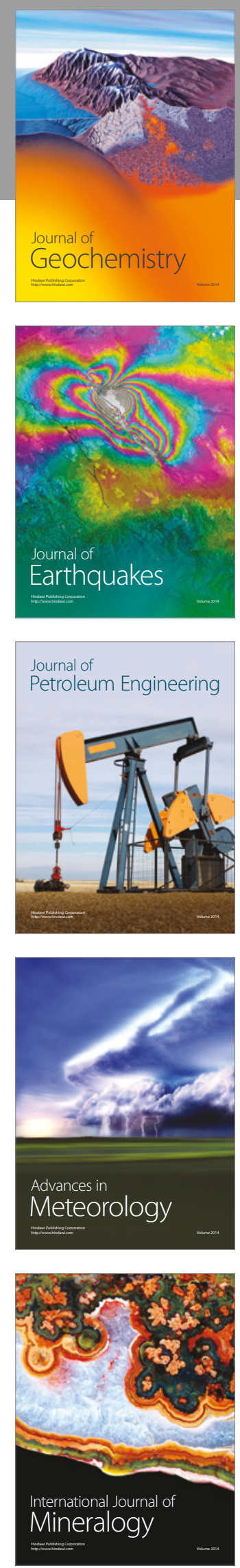
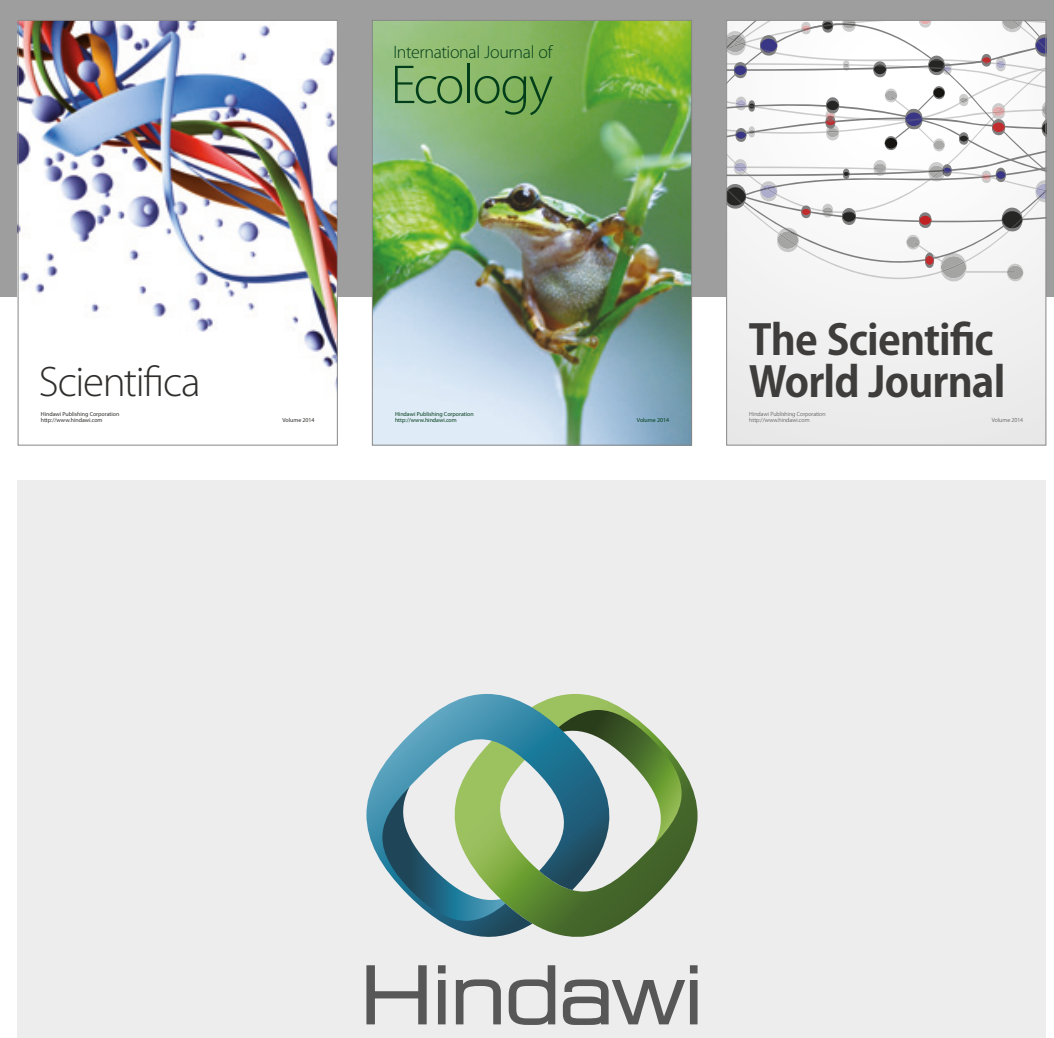

Submit your manuscripts at

https://www.hindawi.com
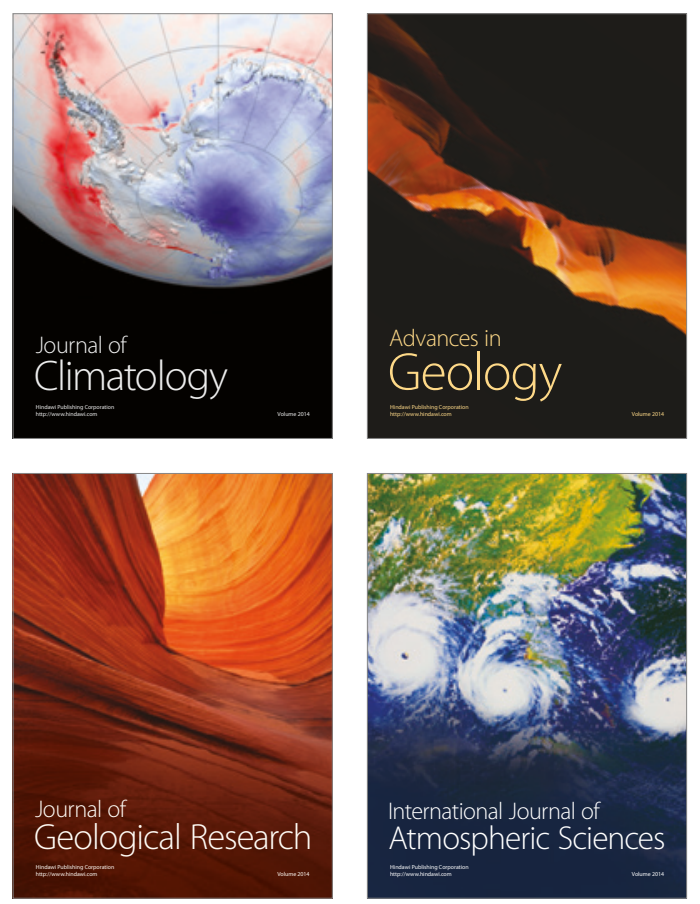

The Scientific

World Journal
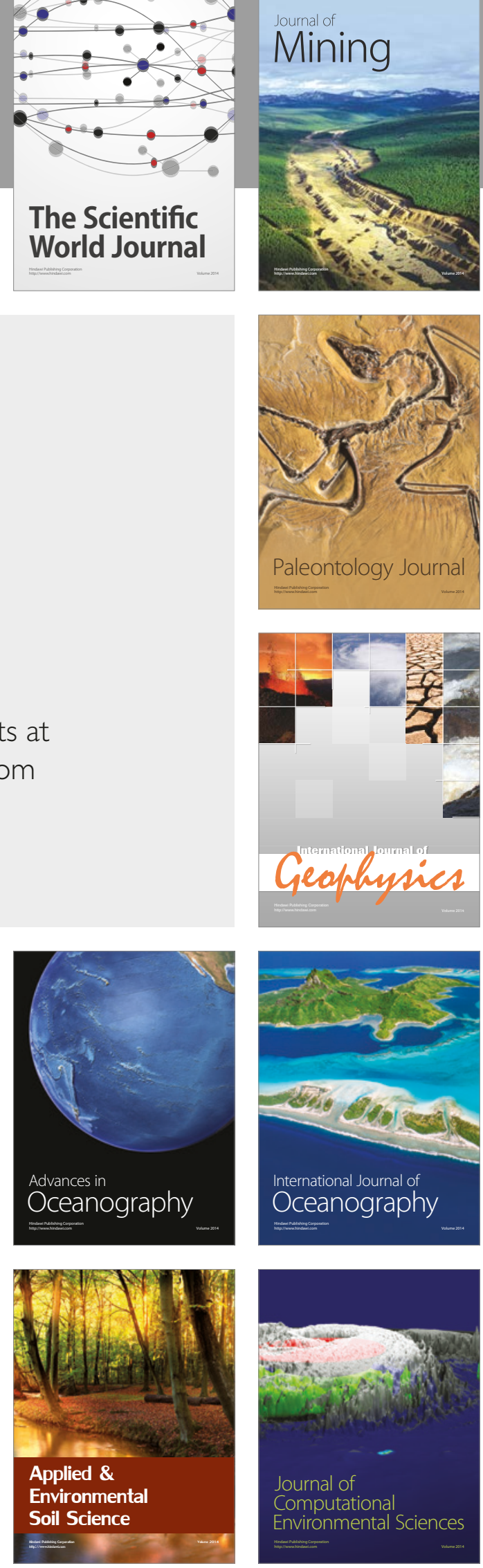